\title{
El arbitraje bajo la nueva Ley Orgánica de Incentivos a las Asociaciones Público Privadas y la Inversión Extranjera
}

\author{
Daniela A. Brito Pusic* y Pablo Cevallos Palomeque** \\ Recibido/Received: 16/12/2015 \\ Aceptado/Accepted: 19/08/2016
}

SUMARIO: 1. Introducción. 2. Breves apuntes sobre la Ley APP. 3. Inclusión de cláusulas arbitrales en los contratos de gestión delegada. 3.1 ¿Se requiere pronunciamiento favorable del Procurador General del Estado para pactar el arbitraje bajo la Ley APP? 3.2 ¿La cláusula arbitral debe ser aprobada por el Comité Interinstitucional de Asociaciones Público - Privadas previsto en la Ley APP? 3.3 Cláusula escalonada. 3.3.1 Carga de agotar la vía administrativa. 3.4 Restricción al arbitraje internacional. 3.5 Potestades regulatoria y tributaria como materias excluidas del arbitraje. 4. Introducción de un novedoso método alterno de solución de conflictos: La Junta de Resolución de Disputas. 5. Propuesta de cláusulas modelos para los contratos de gestión delegada. 5.1 Primer párrafo: mediación o diálogos directos. 5.2 Segundo párrafo: Regulación de la vía administrativa. 5.3 Tercer párrafo: arbitraje administrado o independiente. 6. Conclusiones.

PALABRAS CLAVES: asociación público privada, arbitraje, cláusula escalonada, agotamiento de la vía administrativa, Junta de Resolución de Disputas.

* Abogada Asociada de la firma Apolo Abogados. Abogada por la Universidad Particular de Especialidades Espíritu Santo.

** Abogado Asociado de la firma Apolo Abogados. Abogado por la Universidad Católica de Santiago de Guayaquil. Magister en Derecho Administrativo por la Universidad Católica Santiago de Guayaquil.

D. Brito y P. Cevallos, "El arbitraje bajo la nueva Ley Orgánica de Incentivos a las Asociaciones Público Privadas y la Inversión Extranjera", Revista Ecuatoriana de Arbitraje, No. 7, 2015. 
KEYWORDS: public private partnership, arbitration, multitier clause, exhaustion of the administrative procedures, Dispute Resolution Board.

RESUMEN: Ecuador se apresta a expedir la Ley Orgánica de Incentivos a las Asociaciones Público Privadas y la Inversión Extranjera que busca fomentar la inversión extranjera y nacional en el país, ofreciendo una serie de incentivos económicos y seguridades jurídicas para el inversionista. Entre estos, el proyecto propone la posibilidad de pactar cláusulas arbitrales con el Estado ecuatoriano, a través de los contratos de gestión delegada. No obstante, realizando un análisis de los artículos de la ley se encuentra una cadena de dificultades en su aplicación, los cuales podrían hacer imposible el inicio del arbitraje. A lo largo de este trabajo, se examinarán estos problemas y otras novedades de la ley como la implementación de la Junta de Resolución de Disputas.

ABSTRACT: Ecuador is preparing to enact the Organic Law on Incentives for Public Private Partnerships and Foreign Investment seeking to encourage foreign and domestic investment in the country, offering a range of economic incentives and legal guarantees for investors. Among these, the project proposes the possibility of negotiating arbitration clauses with the Ecuadorian State, through delegated management contracts. However, by analyzing the articles of the law a chain of difficulties can be found in its enforcement, which could make it impossible to start the arbitration. Throughout this paper, these problems and other developments in the law will be analyzed, such as the Dispute Resolution Board.

\section{INTRODUCCIÓN}

Como la historia legislativa lo evidencia, desde el año 2008 el arbitraje como mecanismo de solución de conflictos entre los particulares y el Estado ecuatoriano, se ha restringido enorme- 
mente, tanto en materia de protección de inversiones como en contratación pública. Primero, la Asamblea Nacional Constituyente mediante la expedición de la Constitución de la República del Ecuador (CRE), luego, las disposiciones gubernamentales y, finalmente, las resoluciones del Procurador General del Estado (PGE) han prácticamente eliminado la posibilidad de someter a arbitraje las controversias con el Estado ecuatoriano, luego de que -en un intento por atraer la inversión al país- se había logrado la ratificación de una serie de tratados bilaterales que lo contemplaban.

La CRE creó la base de la restricción del arbitraje, disponiendo que cuando estuviese involucrado el Estado éste sólo podría ser en Derecho y, en materia de contratación pública, debía obtenerse previamente el pronunciamiento favorable del Procurador General del Estado, en los casos establecidos en la Ley ${ }^{1}$. Asimismo, provocó la denuncia de una serie de tratados internacionales, prohibiendo la cesión de jurisdicción soberana a instancias de arbitraje internacional ${ }^{2}$. Por su parte, el Procurador General del Estado expidió un Instructivo ${ }^{3}$ en el que estableció que todo proceso de contratación pública donde se pretenda incorporar cláusulas compromisorias requeriría de su autorización.

Asimismo, el Servicio Nacional de Contratación Pública (SERCOP) (antes Instituto Nacional de Contratación Pública INCOP), mediante resoluciones y modelos obligatorios de pliegos de contratación, inició la restricción requiriendo el pronunciamiento favorable del Procurador para todos los procesos de contratación pública donde se pacten arbitrajes ${ }^{4}$, hasta que finalmente el Gobierno Nacional decidió eliminar la posibilidad de que las

1. Constitución de la República del Ecuador (CRE), Artículo 190, RO No. 449, 20/10/2008.

2. Ídem, Artículo 422.

3. Resolución No. 122, RO No. 254, 27/05/2014.

4. En los formatos obligatorios del SERCOP se contempla la siguiente cláusula modelo: SOLUCIÓN DE CONTROVERSIAS

21.01.- Si se suscitaren divergencias o controversias en la interpretación o ejecución del presente contrato, cuando las partes no llegaren a un acuerdo amigable directo, podrán utilizar los métodos alternativos para la solución de controversias en el Centro de Mediación y Arbitraje (poner nombre del Centro).

Para que proceda el arbitraje en derecho, debe existir previamente el pronunciamiento favorable del Procurador General del Estado, conforme el artículo 190 de la Constitución de la República del Ecuador. 
El arbitraje bajo la nueva Ley Orgánica de Incentivos a

las Asociaciones Público Privadas y la Inversión Extranjera

instituciones que componen la Función Ejecutiva pacten cláusulas arbitrales en los contratos regidos por la Ley Orgánica del Sistema Nacional de Contratación Pública (LOSNCP) ${ }^{5}$.

Sin embargo, una nueva necesidad de inversión en el Ecuador ha hecho al legislador reconsiderar esta postura y permitir nuevamente pactar cláusulas arbitrales, como una herramienta de protección a los gestores privados que decidan asociarse con el Estado. Pero, por los graves síntomas de ostracismo y votos de desconfianza que aún existen hacia este mecanismo, los asambleístas han dispuesto una serie de condicionamientos que dificultan seriamente el acceso a la vía arbitral.

21.02.- En el caso de que se opte por la jurisdicción voluntaria, las partes acuerdan someter las controversias relativas a este contrato, su ejecución, liquidación e interpretación a arbitraje y mediación y se conviene en lo siguiente:

21.02.01.- Mediación.- Toda controversia o diferencia relativa a este contrato, a su ejecución, liquidación e interpretación, será resuelta con la asistencia de un mediador del Centro de Mediación de (ciudad) en el evento de que el conflicto no fuere resuelto mediante este mecanismo de solución de controversias, las partes se someten al Arbitraje de conformidad con las siguientes reglas: 21.02.02.- Arbitraje

- El arbitraje será en Derecho.

- Las partes se someten al Centro de Arbitraje de [...].

- Serán aplicables las disposiciones de la Ley de Arbitraje y Mediación, y las del reglamento del Centro de Arbitraje de [...].

- El Tribunal Arbitral se conformará por un árbitro único o de un número impar según acuerden las partes. Si las partes no logran un acuerdo, el Tribunal se constituirá con tres árbitros. El procedimiento de selección y constitución del Tribunal será el previsto en la Ley y en el Reglamento del Centro de Arbitraje [...].

- Los árbitros serán abogados y preferiblemente con experiencia en el tema que motiva la controversia. Los árbitros nombrados podrán no pertenecer a la lista de árbitros del Centro.

- Los asuntos resueltos mediante el laudo arbitral tendrán el mismo valor de las sentencias de última instancia dictadas por la justicia ordinaria.

- La legislación ecuatoriana es aplicable a este Contrato y a su interpretación, ejecución y liquidación.

- La sede del arbitraje es la ciudad de [...].

- El idioma del arbitraje será el Castellano.

- El término para expedir el laudo arbitral será de máximo 90 días, contados desde el momento de la posesión del (los) árbitro(s).

21.03.- Si respecto de la divergencia o divergencias suscitadas no existiere acuerdo, y las partes deciden someterlas al procedimiento establecido en la Ley de la Jurisdicción Contencioso Administrativa, será competente para conocer la controversia el Tribunal Provincial de lo Contencioso Administrativo que ejerce jurisdicción en el domicilio de la Entidad del sector público. Las entidades contratantes de derecho privado, en este caso, recurrirán ante la justicia ordinaria. (Para este numeral, los pliegos se ajustarán dependiendo de la condición jurídica de la CONTRATANTE).

21.04.- La legislación aplicable a este Contrato es la ecuatoriana. En consecuencia, el CONTRATISTA renuncia a utilizar la vía diplomática para todo reclamo relacionado con este Contrato. Si el CONTRATISTA incumpliere este compromiso, la CONTRATANTE podrá dar por terminado unilateralmente el contrato y hacer efectivas las garantías.

5. Oficio número T.1-C.1-SNJ-12-1134 del 05/10/2012, suscrito por el Secretario General Jurídico de la Presidencia de la República. 
En este artículo analizaremos la posibilidad que otorga la nueva Ley Orgánica de Incentivos a las Asociaciones Público Privadas y la Inversión Extranjera (Ley APP) de incluir métodos alternos de solución de conflictos en los contratos de gestión delegada y los problemas que la propia Ley plantea para su implementación, e intentaremos dar respuesta a una serie de preguntas que surgen de esta ley, pero que su texto no regula, para finalmente brindar al lector posibles soluciones para lograr la aplicabilidad de las cláusulas compromisorias.

A lo largo de este trabajo analizaremos: i) los casos en que se requiere autorización del Procurador General del Estado para pactar arbitraje en el marco de la Ley APP; ii) si las cláusulas compromisorias deben ser aprobadas previamente por el Comité Interinstitucional de Asociaciones Público - Privadas previsto en la Ley APP; iii) la exigencia de que las cláusulas compromisorias sean escalonadas y las complicaciones que esto puede causar al inversionista para acceder al arbitraje pactado, haciendo un énfasis especial en el requerimiento de agotar la vía administrativa; iv) la restricción de los arbitrajes internacionales, que sólo podrían ser conocidos por organismos regionales latinoamericanos; v) la exclusión de las potestades regulatorias y tributaria como materias de discusión en el arbitraje; vi) haremos un breve comentario respecto a la inclusión de un novedoso método alternativo de solución de conflictos: la Junta de Resolución de Disputas; y, vii) Finalmente, plantearemos para la discusión una cláusula modelo para pactar arbitrajes bajo la Ley APP.

\section{Breves apuntes SObRe la Ley APP}

La Ley APP materia de este artículo fue propuesta por el Presidente de la República del Ecuador, en ejercicio de su iniciativa legislativa, con el carácter de proyecto de ley urgente en materia económica, y fue aprobada en primer y segundo debate por la Asamblea Nacional ${ }^{6}$. El principal objetivo de este cuerpo legal es incentivar la inversión, otorgando ciertos beneficios tributarios a 
las compañías que se asocien con el Estado ecuatoriano con el objeto de llevar a cabo proyectos de infraestructura para servicios de interés público, servicios públicos y determinados sectores estratégicos. Estas asociaciones podrán realizarse por delegación del Gobierno Central o de los Gobiernos Autónomos Descentralizados a los gestores privados, mediante contratos de gestión delegada. Los proyectos tendrán como fin proveer bienes, obras o servicios que sean de interés general, y podrán ser total o parcialmente financiados por el Estado ecuatoriano o los inversores pri$\operatorname{vados}^{7}$.

La ley crea el Comité Interinstitucional de Asociaciones Público - Privadas, perteneciente a la Función Ejecutiva, y encargado de coordinar y articular las políticas, lineamientos y regulaciones relativos a las asociaciones Público - Privadas. Este organismo colegiado será el encargado de aprobar los proyectos públicos y aplicar el régimen de incentivos ${ }^{8}$. Con el fin de incentivar la inversión, la Ley APP crea un completo régimen de incentivos, entre los que destacan los beneficios tributarios y la estabilidad jurídica de la normativa que sea declarada como esencial para la inversión. Asimismo, incluye la posibilidad de pactar cláusulas arbitrales y otros mecanismos alternativos de solución de conflictos.

\section{INCLUSIÓN DE CLÁUSULAS ARBITRALES EN LOS CON- TRATOS DE GESTIÓN DELEGADA}

La CRE reconoce, de manera general, los métodos alternativos de solución de conflictos ${ }^{9}$. En materia de contratación pública, el Reglamento a la LOSNCP ha adoptado la implementación de estos mecanismos, señalando la posibilidad de someterse a: arbi-

\footnotetext{
6. A la fecha de presentación de este artículo, 15/12/2015, la Ley está aún en proceso de aprobación. La Asamblea Nacional está debatiendo el veto del Presidente de la República, pero es de anotar que los artículos 19 y 20 que regulan la solución de conflictos, no han sido materia del veto, por lo que conforme al procedimiento legislativo, entrarán en vigencia con el texto aprobado en segundo debate.

7. Ley APP, Artículo 8, RO Sup. No. 652, 18/12/2015.

8. Ídem, Art. 4.

9. CRE, N. 1.
} 
traje, mediación, conciliación, amigable composición y transacción. ${ }^{10}$ Asimismo, en el ámbito de las inversiones, el Código Orgánico de la Producción, Comercio e Inversiones permite someter las controversias ante tres mecanismos: los diálogos directos, la mediación y, por último, el arbitraje $\mathrm{e}^{11}$.

A pesar de encontrarse amplia y legalmente reconocido, el arbitraje con instituciones estatales ha sido fuertemente restringido hasta llegar, en algunas materias, a prohibirse. No obstante, pareciera que la Ley APP busca rectificar esta situación, estableciendo en sus artículos 19 y 20 la posibilidad de pactar cláusulas arbitrales en los contratos de gestión delegada. Pero, lamentablemente, esta nueva esperanza se desvanece rápidamente al notar que, aun cuando teóricamente se puede ir a arbitraje contra el Estado ecuatoriano, se han incorporado varias restricciones materiales y procedimentales. El texto de los citados artículos es el siguiente:

Artículo 19.- Norma General. En el caso de que se sometan las controversias contractuales al arbitraje internacional, este se realizará ante una instancia arbitral regional latinoamericana. Las partes contractuales podrán designar los órganos jurisdiccionales arbitrales en la Región Latinoamericana.

Artículo 20.- Reglas para la Resolución. Para la resolución de controversias que surjan entre las partes respecto de contratos de gestión delegada bajo la modalidad de asociación público - privada suscritos en el marco de la presente Ley, se seguirán las siguientes reglas:

20.1. Cuando la parte que se estime afectada comunique a la otra el objeto de la controversia, estas podrán solucionar la disputa mediante diálogos directos o mediación.

20.2. Si las partes no llegan a un acuerdo que solucione la controversia mediante diálogos directos o mediación y previo

10. Reglamento a la Ley Orgánica del Sistema Nacional de Contratación Pública, Artículo 160, RO Sup. $588,12 / 05 / 2009$.

11. Código Orgánico de la Producción, Comercio e Inversiones (COPCI), Artículo 2, RO Sup. 351, 29/12/2010. 
El arbitraje bajo la nueva Ley Orgánica de Incentivos a

las Asociaciones Público Privadas y la Inversión Extranjera

agotamiento de la vía administrativa, la controversia podrá ser resuelta mediante arbitraje nacional o internacional regional, como última instancia, conforme con lo dispuesto en el contrato de gestión delegada.

No se someterán a arbitraje los asuntos tributarios, así como ningún otro acto que se derive directamente de la potestad legislativa y regulatoria del Estado ecuatoriano.

Le corresponden a la jurisdicción contencioso-administrativa la resolución de las controversias que se susciten respecto de contratos de gestión delegada:

a. Cuando no se haya pactado arbitraje nacional o internacional regional en el contrato de gestión delegada.

b. En los casos que corresponda, si transcurrido el plazo previsto para la notificación al interesado con la resolución que agota la vía administrativa, no se ha ejercido la acción ante la jurisdicción arbitral pactada en el correspondiente contrato de gestión delegada.

Las partes podrán pactar arbitrajes o dictámenes técnicos de conformidad con términos y estipulaciones previstos en el contrato de gestión delegada para resolver controversias puramente fácticas surgidas durante la ejecución o liquidación del respectivo contrato.

La Ley APP deja sin regular ciertos aspectos de gran importancia para la implementación de las cláusulas compromisorias en los contratos de gestión delegada, pues deja sin definir si requieren de pronunciamiento favorable del Procurador General del Estado y de aprobación del Comité Interinstitucional de Asociaciones Público - Privadas. Por otro lado, contempló una serie de condicionamientos que dificultan excesivamente o, incluso, imposibilitan el acceso al arbitraje al inversionista. La Ley APP exige que -para someter cualquier controversia surgida de los contratos de gestión delegada- se cumpla con un proceso de negociación obligatoria entre las partes, a través de mediación o diálogos directos, y, posteriormente, exige el agotamiento de la vía 
administrativa. Adicionalmente, se restringe el arbitraje excluyendo el conocimiento de materias esenciales, y se limita el arbitraje internacional a la región latinoamericana. A continuación, plantearemos nuestras respuestas a estas interrogantes.

\section{1 ¿Se requiere pronunciamiento favorable del Procurador General del Estado para pactar el arbitraje bajo la Ley APP?}

La Ley APP no determina si es necesario o no obtener la autorización previa del Procurador General del Estado para pactar arbitrajes nacionales o internacionales en el ámbito de los contratos de gestión delegada. Los artículos 19 y 20 regulan varios aspectos de los arbitrajes, pero no modifican las reglas para pactar arbitrajes por parte del sector público. En tal virtud, consideramos que la Ley APP no modifica el esquema general de autorizaciones previas previstas en el ordenamiento jurídico ecuatoriano para el arbitraje. Los artículos 190 y 422 de la CRE, los artículos 4 y 42 de la Ley de Arbitraje y Mediación (LAM), el artículo 11 de la Ley Orgánica de la Procuraduría General del Estado (LOPGE), y las reglas del Instructivo de Arbitraje expedido por la Procuraduría General del Estado, de ninguna forma se ven reformados o derogados, por la entrada en vigencia de la Ley APP.

No habiéndose modificado el esquema general de autorizaciones previas, es necesario dilucidar si bajo el artículo 190 de la CRE, los contratos sometidos a la Ley APP deben considerarse como parte de la materia de "contratación pública" regulada por dicho artículo. La respuesta la encontramos en la legislación y demás normativa secundaria, tales como la LOSNCP, su Reglamento, la normativa secundaria expedida por el SERCOP, y el Instructivo de Arbitraje de la Procuraduría General del Estado, que establecen lo que en términos de nuestra legislación debe entenderse como contratación pública, circunscribiéndolo al ámbito de los contratos regulados por la LOSNCP. 
El artículo 1 del Instructivo de Arbitraje de la Procuraduría General del Estado parece así indicarlo, al establecer los casos en que se requiere de su autorización para pactar cláusulas arbitrales, y en los mismos no se incluye todo el espectro de relaciones contractuales que puede pactar el Estado ecuatoriano. Por ejemplo, no se incluyen las delegaciones a la iniciativa privada reguladas por el Código de la Producción, Comercio e Inversiones (COPCI) y por el Código Orgánico de Organización Territorial, Autonomías y Descentralización (COOTAD), ni los mecanismos asociativos contemplados en la Ley Orgánica de Empresas Públicas. Por otro lado, la Corte Constitucional ha establecido que en el artículo 190 la expresión "contratación pública" debe entenderse como:

la relación contractual del Estado con las entidades del sector público y privado, relacionadas, por ejemplo, con licitaciones, concurso público de ofertas, etc., mismas que según mandato constitucional están obligadas a realizar un arbitraje en derecho.- Por otra parte, en lo que se refiere al Estado ecuatoriano como sujeto de derecho y obligaciones internacionales, como las originadas como la contratación de deuda externa, que es el caso, las reglas aplicables son las contenidas en el artículo 422 inciso final[ $\ldots]^{12}$

Si bien las expresiones de la Corte Constitucional no son del todo claras, admiten la posibilidad de que no todas las relaciones contractuales del Estado se deben considerar como contratación pública, y desde nuestro punto de vista, las relaciones contractuales suscritas bajo la Ley APP, difieren esencialmente de las relaciones contractuales suscritas bajo la LOSNCP, especialmente en la distribución de los riesgos y en su financiamiento, pues los contratos suscritos bajo la LOSNCP se financian con fondos públicos y su disponibilidad se debe certificar, mientras que las asociaciones público privadas están concebidas esencialmente para que el sector privado realice inversiones en materias reservadas para el Estado.

12. Corte Constitucional para el Periodo de Transición. Sentencia Interpretativa No. 0001-09-SIC-CC, Caso No.0005-09-IC, 16/03/2009, RO No. 549. 
Podemos deducir que bajo el artículo 190 de la CRE, no todo contrato suscrito por una institución del Estado debe ser considerado como "contratación pública", pues dicha expresión en ese artículo tiene un alcance definido en la legislación. Encontramos que, conforme a la legislación vigente, para someterse a arbitraje nacional en el marco de un contrato suscrito bajo la Ley APP, solo se requerirá contemplar la cláusula arbitral en el Contrato de Gestión Delegada que se suscriba (artículo 4 LAM Y 20.2 Ley APP), cumpliendo con los requisitos previstos en el referido artículo 4 de la LAM y en los propios artículos 19 y 20 de la Ley APP. Para someterse a arbitraje internacional, se requerirá además obtener previamente la autorización del Procurador General del Estado (Art. 190 CRE, Art. 42 LAM).

Ahora nos corresponde dilucidar un aspecto final: ¿En qué momento debe obtenerse la autorización del Procurador General del Estado? ¿Antes de la aprobación del proyecto por el Comité Interinstitucional de APP, o después de dicha autorización? Para contestar esta pregunta, debemos acudir a las normas generales de arbitraje: en caso de pactarse arbitrajes internacionales en los Contratos de Gestión Delegada, deberá solicitarse la autorización del Procurador General del Estado previo a la firma del Contrato, sobre la base de la versión final y definitiva del contrato, conforme lo exige el artículo 4 letra a) del Instructivo de Arbitraje.

Nuevamente, no hay modificación al régimen general de autorizaciones previas en materia arbitral, aunque convendría analizar la posibilidad de que mediante normativa secundaria, dicha cláusula pueda aprobarse antes del respectivo concurso público para contratar al gestor privado, justamente para evitar incertidumbre jurídica o cambio de reglas durante el proceso de contratación. 


\section{2 ¿La cláusula arbitral debe ser aprobada por el Comité Interinstitucional de Asociaciones Público - Privadas previsto en la Ley APP?}

La respuesta a esta pregunta la encontramos en los artículos 6, 9 y 12 de la Ley APP, en la cual se describe el alcance de la autorización que otorga el Comité Interinstitucional. El artículo 6 contempla entre las atribuciones del Comité Interinstitucional la siguiente: "6.3.- Aprobar, a propuesta de la entidad delegante, los proyectos que se desarrollarán bajo la modalidad de asociación público-privada y el régimen de incentivos previsto en esta Ley". Por su parte, el inciso segundo del artículo 9 establece que corresponde a la autoridad delegante "requerir al Comité Interinstitucional la aprobación del proyecto público, aplicación de los incentivos y beneficios previstos en esta Ley para los proyectos públicos que se promuevan." El primer inciso del artículo 12 de la Ley APP establece que:

[1]a selección del gestor privado se efectuará mediante concurso público, convocado por la entidad delegante, previa aprobación del proyecto público por parte del Comité Interinstitucional. Para ello, la entidad delegante formulará el pliego de bases administrativas, técnicas y económico-financieras, los términos contractuales que regirán, en su caso, el procedimiento y la relación entre la entidad delegante y el gestor delegado.

De la lectura del articulado citado, podemos concluir que el pronunciamiento del Comité Interinstitucional se limita a la aprobación del proyecto y sus incentivos y beneficios. Corresponderá al propio Comité Interinstitucional definir como se deberá presentar el proyecto a ser conocido y aprobado por el Comité Interinstitucional, bien sea a nivel de perfil de proyecto, a nivel de estudio de factibilidad, o a nivel de diseños definitivos, y el alcance de la información que deberá conocer el Comité. Para ello, el Comité deberá expedir las guías generales y notas técnicas previstas en el artículo 6.5 de la Ley APP. En todo caso, parece claro 
a nuestro análisis que las condiciones contractuales, incluyendo la cláusula arbitral que se incluya, no deberá ser sometida a aprobación del Comité Interinstitucional.

\subsection{Cláusula escalonada}

La Ley obliga a las partes a cumplir un estricto procedimiento, constituido por dos etapas, para poder someter su controversia a un arbitraje. El cumplimiento de estas etapas es un requisito esencial que debe ser observado y cumplido, pues, en su defecto, el arbitraje no podrá celebrarse. En la negociación del contrato, si las partes desean incorporar una cláusula arbitral, deberán decidir si, al momento de suscitarse una controversia entre ellas, acudirán a una mediación o dialogarán directamente para intentar resolver su diferencia.

De este modo, en el momento en el que nace la controversia, la parte que se sienta perjudicada deberá informarle a la otra de esta situación, con el objeto de iniciar la mediación o los diálogos directos. Si las partes no pudieren llegar a un acuerdo que dé fin a sus conflictos, la parte que se sienta afectada deberá, por mandato de la Ley, iniciar acciones ante la institución estatal hasta agotar la vía administrativa. Si agotada la vía administrativa, aún no se ha podido resolver la controversia, la parte que se sienta afectada (el inversionista o contratista) recién podría presentar una solicitud de inicio de arbitraje.

Esta modalidad es conocida como cláusula escalonada. La cláusula escalonada es una estipulación contractual que prevé diferentes etapas que las partes deben cumplir antes de comenzar el arbitraje, con el fin de llegar a soluciones amigables, evitando la confrontación. El arbitraje se realizará si todos los esfuerzos para arreglar la disputa han fallado ${ }^{13}$. Se entiende que una cláusula es escalonada cuando en la misma se prevé dos o tres métodos distintos para solucionar las controversias, que deben

13. A. Jolles, Consequences of Multi-tier Arbitration Clauses: Issues of Enforcement, Sweet \& Maxwell Limited, 2006, pp. 329-338. 
realizarse en un orden predeterminado por las partes, siendo el arbitraje, usualmente, el último escalón. En estos casos, las partes pretenden obligarse a sí mismas a intentar resolver amistosamente sus diferencias, arriesgándose a una objeción de admisibilidad en el arbitraje, en caso de no hacerlo o no cumplir adecuadamente con estos mecanismos ${ }^{14}$.

Uno de los mayores problemas de este tipo de cláusulas es que dificultan el inicio de un arbitraje, pudiendo incluso impedir el acceso al arbitraje a una de las partes. Esta dificultad se da por la falta de delimitación de las partes a las etapas pre-arbitrales, lo cual en algunos casos hace imposible determinar cuándo éstas se han cumplido y permiten que la otra parte obstruya el inicio del arbitraje, alegando la falta de cumplimiento de las etapas pre-arbitrales ${ }^{15}$.

Las partes que quieran someter sus controversias a arbitraje, en la modalidad de contratos establecidas en esta ley, deben tener en consideración esta situación, por lo que, al momento de elaborar el contrato, deben pactar expresamente los tiempos y regular los mecanismos, estableciendo de qué formas se entienden cumplidas las etapas pre-arbitrales. En este caso tenemos dos mecanismos alternos de solución de conflictos, entre los que tenemos que elegir: diálogos directos y mediación.

Consideramos que la mediación es un mecanismo que brinda mayores seguridades a las partes. En primer lugar, el procedimiento de la mediación es estructurado y ya se encuentra regulado en nuestra legislación. En este sentido, podemos claramente conocer cuándo comienza y termina, y el procedimiento que debe seguirse para entenderse cumplida. En segundo lugar, interviene una tercera persona imparcial, en calidad de mediador, que se encuentra involucrada en el proceso, quien conduce el procedimiento. En tercer y último lugar, y creemos que es uno de los puntos más importantes, es que cuando ha sido imposible llegar

14. D. JimÉnez Figueres, "Multi-Tiered Dispute Resolution Clauses in ICC Arbitration”, ICC International Court of Arbitration Bulletin Vol. 14(1), Spring, 2003, pp. 71-73.

15. A. Jolles, N. 13. 
a un acuerdo, o aún en el caso de que la otra parte se niegue a mediar o simplemente no participe, la mediación concluye con un acta de imposibilidad. Este documento permite demostrar ante cualquier autoridad, que se ha cumplido la etapa pre-arbitral escogida por las partes.

Ahora, respecto a los diálogos directos es menester resaltar que este mecanismo consiste en meras negociaciones que realizan las partes sin intervención de terceras personas ni un procedimiento determinado, es decir, las partes deben intentar resolver sus conflictos directamente entre ellas. Es nuestra opinión que convenir los diálogos directos como una etapa arbitral, podría acarrear graves consecuencias por su falta de estructura y regulación. En primer lugar, para que las negociaciones se realicen se necesita la cooperación de todas las partes involucradas, y muchas veces las partes no están interesadas en negociar o buscan evadir las negociaciones para obstruir el arbitraje. En segundo lugar, no hay límite de tiempo para la duración de los diálogos directos, por lo que es complejo determinar en qué momento se entiende cumplida la etapa pre-arbitral. En tercer lugar, no existe una forma establecida o comúnmente aceptada para comprobar que fue imposible llegar a un acuerd y que las negociaciones han llegado a su fin, cuando no existe cooperación o la otra parte pretende obstruir el arbitraje.

Estimamos que si las partes desean solucionar sus controversias amistosamente, sin intervención de terceros, no necesitan estipularlo en el contrato para negociar directamente antes de someter sus controversias a arbitraje. No obstante, en el caso de que las partes quieran incluir este mecanismo en sus cláusulas recomendamos que determinen: (i) plazo; (ii) procedimiento; $y$, (iii) forma de demostrar el cumplimiento de la etapa pre-arbitral.

\subsubsection{Carga de agotar la vía administrativa}

Debemos iniciar por apuntar que -desde la perspectiva de las relaciones entre el Estado y los ciudadanos- la necesidad del 
agotamiento de la vía administrativa para iniciar acciones legales contra el Estado fue percibido en su momento como una disposición ya superada ${ }^{16}$. El artículo 38 de la Ley de Modernización del Estado, Privatizaciones y Delegación a la Iniciativa Privada reformó tácitamente la obligación contenida en el artículo 30 letra e) de la Ley de la Jurisdicción Contencioso Administrativa, como era acreditar ante el Tribunal Distrital de lo Contencioso Administrativo haber agotado la vía administrativa, es decir, la vía de reclamo ante la propia institución pública demandada o sus superiores jerárquicos. Esta línea de regulación ha sido continuada por el Código Orgánico General de Procesos (COGEP), tal como se puede apreciar en su artículo 300.

A pesar de ello, la Ley APP -recogiendo un criterio ya anticipado por el COPCI- exige que para iniciar un arbitraje nacional o internacional en el ámbito de las asociaciones público-privadas, se requiere haber agotado previamente la vía administrativa. Así, el artículo 20.2 de la Ley APP establece expresamente que:

[s]i las partes no llegan a un acuerdo que solucione la controversia mediante diálogos directos o mediación y previo agotamiento de la vía administrativa, la controversia podrá ser resuelta mediante arbitraje nacional o internacional regional, como última instancia, conforme lo dispuesto en el contrato de gestión delegada.

Desde varios análisis, exigir el agotamiento de la vía administrativa puede considerarse como un retroceso en la regulación de las relaciones de los particulares con el Estado, pues impone al particular una carga administrativa adicional, y además genera una serie de problemas de interpretación y aplicación de los artículos 19 y 20 de la Ley APP, como veremos a continuación.

En principio, encontramos que exigir el agotamiento de la vía administrativa nos obliga a contestar las siguientes preguntas: ¿Cuándo se agota la vía administrativa? ¿Qué régimen jurídico regula el fin de la vía administrativa? ¿Qué pasa si la entidad de-

16. E. Pérez Camacho, Derecho Administrativo, Tomo 2, 2006. p. 601. 
legante no contesta los recursos administrativos? ¿Qué plazo tengo para iniciar el arbitraje una vez agotada la vía administrativa? Todas las preguntas planteadas no tienen respuesta en los artículos de la Ley APP y, como demostraremos, tampoco tienen una única respuesta en la legislación vigente. Anticipamos que la única alternativa que encontramos para resolver los inconvenientes que genera la exigencia del agotamiento de la vía administrativa, es la regulación de estos aspectos en la cláusula arbitral, sea por medio de su regulación expresa o mediante la remisión a un cuerpo legal específico.

La primera dificultad consiste en determinar cuándo se puede considerar agotada la vía administrativa. Debemos resaltar que no hay una única regulación sobre este aspecto, pues existen al menos dos regímenes aplicables en función del nivel de gobierno que se trate, sea Función Ejecutiva o gobiernos autónomos descentralizados. Si se trata de un proyecto a ser desarrollado por una entidad de la Función Ejecutiva, encontramos que el Estatuto del Régimen Jurídico Administrativo de la Función Ejecutiva (ERJAFE), en sus artículos 179 y siguientes, regula expresamente el agotamiento de la vía administrativa y establece normas relacionadas con los recursos administrativos:

\section{Art. 179.- Fin de la vía administrativa.}

Ponen fin a la vía administrativa:

Las resoluciones de los recursos de apelación y revisión;

Las resoluciones de los órganos administrativos que carezcan de superior jerárquico, salvo que una ley establezca lo contrario;

Las demás resoluciones de órganos administrativos cuando una disposición legal o reglamentaria así lo establezca; y, Los acuerdos, pactos, convenios o contratos que tengan la consideración de finalizadores del procedimiento.

Sin embargo, y a pesar de la aparente claridad de este artículo, debemos apuntar que los artículos 2 y 100 del ERJAFE limitan la aplicación de las normas sobre el fin de la vía administrativa a los organismos de la Administración Pública 
Central (Presidencia, Vicepresidencia, ministerios), y excluye de su aplicación a los organismos de la Administración Pública Institucional (entidades creadas por o en virtud de una ley, personalidad jurídica y patrimonio propio $)^{17}$. Considerando estos artículos, vemos que hay una parte de la Función Ejecutiva que no tendría regulaciones sobre el fin de la vía administrativa, lo cual sin duda puede ser fuente de incertidumbre y de dificultades en la aplicación de los artículos 19 y 20 de la Ley APP.

Por otro lado, si el proyecto de asociación público privado lo promueve un gobierno autónomo descentralizado, el agotamiento de la vía administrativa se encuentra regulado en los artículos 364 y siguientes del Código Orgánico de Organización Territorial, Autonomías y Descentralización (COOTAD), y de manera especial los artículos 404 y siguientes que regulan los recursos administrativos, donde se establecen plazos para la interposición de los recursos administrativos y los efectos de la resolución de los recursos administrativos. En el COOTAD no hay un artículo donde expresamente se defina el fin de la vía administrativa, pero dado que sus normas guardan similitud con las normas del ERJAFE, creemos que son aplicables los mismos criterios establecidos en el artículo 179 trascrito arriba.

Una dificultad que genera el agotamiento de la vía administrativa regida por las normas existentes, como son el ERJAFE y el COOTAD, es que tratándose de procedimientos reglados, el administrado tiene plazos fatales que cumplir. Así, si dentro de una relación contractual bajo la Ley APP, el Estado dicta una resolución, y la misma no es recurrida dentro de los plazos previstos en las normas citadas, entonces se entiende que el acto o resolución está en firme y que el administrado ya no puede recurrirlo. Entonces surge la duda: Si el gestor privado no interpone los recursos administrativos dentro de plazo, ¿Se entiende que ha renunciado al arbitraje? La no interposición de un recurso no consta como hecho finalizador de la vía administrativa conforme al artículo 179 del ERJAFE. Sin embargo, en la realidad práctica, 
el gestor privado siempre va a tener la vía del recurso extraordinario de revisión, que tiene plazos extensos de hasta 3 años, tanto en el ERJAFE como en el COOTAD.

Existen dos dificultades adicionales que plantea el agotamiento de la vía administrativa: El agotamiento de la vía administrativa cuando la entidad delegante no contesta los recursos administrativos, y el inicio del cómputo del plazo para interponer la demanda arbitral conforme al tercer inciso, letra b) del artículo 20 de la Ley APP.

Cuando la institución pública no contesta los recursos administrativos, la solución prevista por la normativa de la Función Ejecutiva (Art. 115 ERJAFE y 28 de la Ley de Modernización) y de los gobiernos autónomos descentralizados (Art. 387 del COOTAD) es la aplicación del silencio administrativo positivo, es decir, se entiende dictada la resolución a favor del administrado. Sin embargo, nos encontramos con una dificultad práctica, como es el reiterado criterio jurisprudencial establecido por la Sala de lo Administrativo de la Corte Suprema de Justicia, según el cual el silencio administrativo no es aplicable en las relaciones contractuales con el Estado, toda vez que dichas relaciones se rigen por las disposiciones previstas en el contrato que se trate, so pena de permitir modificaciones unilaterales de las relaciones contractuales ${ }^{18}$.

Al no ser aplicable el silencio administrativo, eso impide el agotamiento de la vía administrativa si acaso la entidad delegante se niega a dar respuesta a las solicitudes del gestor privado. En tal virtud, es necesario que el propio Contrato de Gestión Delegada regule el fin de la vía administrativa, de tal forma que se prevea el curso de acción a seguir y los plazos a cumplir en caso de silencio administrativo de la entidad delegante. De esta forma, se vuelve palpable la necesidad de regular el fin de la vía administrativa, pues la propia jurisprudencia contencioso administrativa ha exigido que estos aspectos sean materia de regulación

18. Sala de lo Contencioso Administrativo, Corte Suprema de Justicia, Gaceta Judicial, Serie XVIII, No. 1, 04/10/2004, p. 275; Sala de lo Contencioso Administrativo, Corte Suprema de Justicia, RO Sup. No. 17 , Cas. $267,13 / 05 / 2005$. 
contractual.

Finalmente, y quizá el más complejo de los problemas a resolver frente al agotamiento de la vía administrativa, consiste en determinar cuándo empieza a decurrir el plazo para presentar la demanda arbitral, una vez que se agota la vía administrativa. La redacción del artículo 20 inciso tercero, letra b), genera una evidente contradicción que hace imposible su aplicación:

Le corresponde a la jurisdicción contencioso-administrativa la resolución de las controversias que se susciten respecto de los contratos de gestión delegada:

[...] b) En los casos que corresponda, si transcurrido el plazo previsto para la notificación al interesado con la resolución que agota la vía administrativa, no se ha ejercido la acción ante la jurisdicción arbitral pactada en el correspondiente contrato de gestión delegada.

Como puede leerse con claridad, por un lado el artículo exige agotar la vía administrativa previo al inicio del proceso arbitral, pero por otro lado establece que la demanda arbitral deberá presentarse dentro del plazo que tienen la entidad delegante para notificar el fin de la vía administrativa. Es decir, si el gestor privado plantea un recurso administrativo y conforme a la normativa aplicable el plazo previsto para contestar dicho recurso es de dos meses, esos mismos dos meses son el plazo para plantear la demanda arbitral. De no plantearse el arbitraje dentro de ese plazo, la jurisdicción arbitral pierde competencia, pero si dentro de los dos meses anotados no se agota la vía administrativa, el gestor privado se ve impedido de acudir al arbitraje. Es una verdadera situación de Catch $22^{19}$.

Para corregir la inconsistencia planteada por el artículo citado, es necesario desarrollar en la cláusula arbitral los plazos

19. Nos referimos al dilema que plantea el autor judío Joseph Heller en su libro de ficción Catch 22, según el cual se exigía a los pilotos del ejército de Estados Unidos estar mentalmente sanos para pilotear en una misión de combate, pero las misiones eran tan peligrosas que el piloto que demostraba deseos de volar, era inmediatamente descalificado, porque solo un loco podía querer volar en esas condiciones. Y si estando descalificado para volar el piloto llenaba la solicitud para pedir su regreso a casa, este era inmediatamente calificado para una misión, porque querer ir a casa demostraba que el piloto estaba mentalmente sano. 
para iniciar el arbitraje, y aclarar el inicio del cómputo del plazo, pues de lo contrario la cláusula puede tornarse de imposible aplicación, y la misma será una fuente inagotable de conflicto entre las partes al momento de plantear la competencia del tribunal arbitral y los aspectos procedimentales del arbitraje.

Concluimos que para evitar todas las dificultades apuntadas, la cláusula arbitral debe regular el fin de la vía administrativa. El escalonamiento de la cláusula ya analizado, demanda la regulación de plazos y la aclaración de las etapas a agotarse previo al inicio de la demanda arbitral "como última instancia", por lo que lo más recomendable para evitar los conflictos que puede generar la interpretación sobre el agotamiento de la vía administrativa, es que las partes pacten todos estos aspectos. Consideramos que los vacíos normativos ya señalados sobre el fin de la vía administrativa, exigirán que las partes acuerden los mecanismos que mejor convengan a sus intereses. Por otro lado, bien puede el Comité Interinstitucional de Asociaciones Público - Privadas, en ejercicio de su función establecida en los artículos 6.5. y 11 de la Ley APP, zanjar el asunto de manera definitiva estableciendo condiciones obligatorias respecto de este punto.

Como puede verse, el agotamiento de la vía administrativa genera más de una dificultad en la ejecución de la cláusula arbitral, y por tanto puede ser materia de inseguridad jurídica.

\subsection{Restricción al arbitraje internacional}

Celebramos que la Ley reconozca para los inversionistas extranjeros el arbitraje internacional como mecanismo de solución de controversias que puedan suscitarse con el Estado ecuatoriano respecto de su inversión. No obstante, surgen preocupaciones al plantearse una norma que limita al arbitraje a administrarse exclusivamente ante instituciones latinoamericanas:

Artículo 19.- Norma General. En el caso de que se sometan las controversias contractuales al arbitraje internacional, este 
El arbitraje bajo la nueva Ley Orgánica de Incentivos a

las Asociaciones Público Privadas y la Inversión Extranjera

se realizará ante una instancia arbitral regional latinoamericana. Las partes contractuales podrán designar los órganos jurisdiccionales arbitrales en la Región Latinoamericana.

En este punto, es menester destacar que no existe actualmente ningún organismo que administre arbitrajes que sea propiamente latinoamericano, por poner el ejemplo más cercano, la Comisión Interamericana de Arbitraje Comercial (CIAC), quien tiene incluso sede en el Ecuador, es una organización interamericana ${ }^{20} \mathrm{y}$ la ley exige específicamente que sea latinoamericano. Con esta disposición legal se excluye la posibilidad de someter las controversias a reconocidos y experimentados organismos internacionales de arbitraje, como es el caso de la Cámara de Comercio Internacional (ICC), el American Arbitration Association (AAA), el International Centre for Dispure Resolution (ICDR), London Court of International Arbitration (LCIA), entre otros.

Esta regla restringe la libertad de los contratantes a someter sus controversias a un selectivo número de centros. Siendo más concretos, el arbitraje internacional sólo podrá someterse a los centros de arbitraje autorizados en el país que estén habilitados para conocer y administrar arbitrajes internacionales, como el Centro de Arbitraje y Mediación de la Universidad de Especialidades Espíritu Santo, el Centro de Arbitraje y Mediación de la Cámara de Comercio Ecuatoriano Americana y el Centro de Arbitraje y Conciliación de la Cámara de Comercio de Guayaquil, entre otros.

La otra posibilidad es someter sus arbitrajes internacionales a los Centros de Arbitraje de países extranjeros de la región, que puedan administrar arbitrajes internacionales como es el caso del Centro de Arbitraje y Mediación de la Cámara de Comercio de Lima, el Centro de Arbitraje y Conciliación de la Cámara de Comercio de Bogotá, el Centro de Arbitraje y Mediación de la Cámara de Comercio de Santiago. Otra alternativa poco explo-

20. La expresión "Interamericano" incluye a los Estados Unidos de América, Canadá y los países angloparlantes del Caribe. 
rada son los tribunales arbitrales independientes con sede en Latinoamérica, pero los mismos son menos comunes en arbitrajes de inversión, por la ausencia de regulaciones y de institucionalidad propios de este tipo de arbitrajes.

Esta limitación tiene su origen en el artículo 422 de la CRE, que prohíbe ceder jurisdicción soberana a instancias de arbitraje internacional en contratos celebrados con particulares, con una excepción: cuando se traten de solución a controversias entre Estados y ciudadanos en Latinoamérica por instancias arbitrales regionales. Este artículo, creemos los autores, apunta principalmente al proyecto de arbitraje en la Unión de Naciones Suramericanas UNASUR, pero hasta que este proyecto se cristalice, las opciones se limitan a las ya señaladas.

\subsection{Potestades regulatoria y tributaria como materias excluidas del arbitraje}

El segundo inciso del artículo 20 de la Ley APP contiene el siguiente texto: "No se someterán a arbitraje los asuntos tributarios, así como ningún otro que se derive directamente de la potestad legislativa y regulatoria del Estado ecuatoriano". Esta norma contiene una exclusión de las materias arbitrables en los contratos de Gestión Delegada regulados bajo la Ley APP. Sin embargo, a pesar de que el texto parece claro respecto de las materias excluidas, estamos seguros que en su aplicación dicha exclusión puede generar más de una dificultad, como las que enumeraremos a continuación.

El artículo 15 de la Ley APP contempla uno de los incentivos contemplados en dicha Ley, como es la estabilidad jurídica de los aspectos regulatorios sectoriales y específicos que hayan sido declarados como esenciales en los correspondientes contratos de gestión delegada. Es decir, que esta Ley permite otorgar estabilidad jurídica a las regulaciones propias del servicio o de la materia a la que se refiere el contrato de gestión delegada. Así, en el con- 
trato de gestión delegada se podrá pactar, por ejemplo, tratándose de una obra portuaria, que durante la vigencia del Contrato se mantienen vigentes las disposiciones de la Ley de Puertos.

Por otro lado, las disposiciones reformatorias primera y segunda de la Ley APP contienen reformas al COPCI, así como reformas a la Ley Orgánica del Régimen Tributario Interno (LORTI). En dichas reformatorias se contemplan los incentivos tributarios que se otorgarán a los Contratos de Gestión Delegada, los cuales ya fueron enumerados en la segunda sección de este artículo.

De lo dicho, podemos observar que los principales incentivos que otorga la Ley APP, son justamente la estabilidad tributaria y regulatoria, pero al mismo tiempo, se excluyen del arbitraje los asuntos tributarios o aquellos derivados de la potestad legislativa y regulatoria del Estado. Es decir, que uno de los aspectos esenciales de la relación que se va a entablar entre la entidad delegante y el gestor privado, se las debe considerar como no arbitrable. Es un mensaje contradictorio y confuso para el gestor privado que, por un lado, se otorguen tan importantes incentivos, pero que, al mismo tiempo, estos incentivos se excluyan expresamente del arbitraje que se propone en la Ley.

La estabilidad tributaria y regulatoria debe ser claramente reglada en el Contrato, por exigencia del artículo 16 de la Ley APP y porque es necesario para las partes definir los efectos jurídicos y alcance de la estabilidad jurídica, y el incumplimiento de la misma por parte de la entidad delegante o de parte de cualquier organismo del Estado. Tratándose de un compromiso contractual que afecta a la vigencia en el tiempo de normativas tributarias y sectoriales, necesariamente la suscripción del contrato de gestión delegada va a afectar la gestión de otras entidades públicas de altísima importancia, como pueden ser el Servicio de Rentas Internas (SRI), el Servicio Nacional de Aduana del Ecuador (SENAE), la Asamblea Nacional e incluso al propio Presidente de la República. 
En tal virtud, surge la siguiente inquietud: ¿El incumplimiento de la estabilidad tributaria y regulatoria pactada en el contrato de gestión delegada, es materia arbitrable bajo la Ley APP? Es claro que los conflictos relacionados con la aplicación de la ley tributaria a un caso concreto no es materia arbitrable, como tampoco es arbitrable el conflicto que pueda surgir por la aprobación de una normativa sectorial determinada. Sin embargo, si el Estado ecuatoriano, o en particular la entidad delegante, incumple la obligación contractual de otorgar estabilidad tributaria y/o regulatoria sectorial, y el contrato prevé un efecto jurídico para dicho incumplimiento, consideramos que dicho incumplimiento contractual puede ser arbitrable, toda vez que no se estaría discutiendo directamente la interpretación o aplicación de una norma tributaria o sectorial, sino el efecto jurídico del incumplimiento contractual.

Así, por ejemplo, si el incumplimiento de la estabilidad tributaria está previsto como una causa de terminación del contrato, el gestor privado estaría autorizado para iniciar un arbitraje para obtener una declaración de incumplimiento contractual por parte del Estado, la terminación del contrato y la indemnización de daños y perjuicios que corresponda. Por el contrario, si el conflicto se refiere a la nulidad de una determinación tributaria, o a una devolución de impuestos pagados en exceso, dicho conflicto no es arbitrable, por tratarse estrictamente de asuntos tributarios.

Desde nuestro punto de vista, una determinación tributaria, o la expedición de una norma sectorial, no pueden ser sometidas a arbitraje, pero si la determinación tributaria o la expedición de la norma sectorial configuran un incumplimiento contractual al que el contrato de gestión delegada le asigna un efecto jurídico determinado, dicho incumplimiento es materia arbitrable.

Por otro lado, pueden existir casos donde los asuntos tributarios y/o sectoriales no constituyen incumplimiento del contrato de gestión delegada, por no estar referidas a normas cuya estabilidad se ha garantizado. Así, por ejemplo, si el SRI determina que 
ciertos servicios están gravados con tarifa doce, y el gestor privado los factura con tarifa cero, la decisión sobre la tarifa aplicable no es materia arbitrable, o si se determina que se han retenido impuestos de terceros y que los mismos no han sido pagados, o una reforma tributaria que involucre aspectos que no sean objeto de estabilidad en el contrato de gestión delegada, entre otros casos donde el conflicto tributario no entraña discusión de la estabilidad jurídica y tributaria establecida en el contrato de gestión delegada.

Es por ello que creemos que debe distinguirse con claridad que la aplicación de normas tributarias y/o normativas sectoriales no es arbitrable cuando ello no entrañe una violación de la estabilidad garantizada en el contrato de gestión delegada conforme al artículo 15 de la Ley APP. Sabemos que trazar una línea divisoria no es tarea sencilla, más aún si el contrato de gestión delegada no enfrenta de manera adecuada estos temas en sus cláusulas, o si la cláusula arbitral no aporta luces para establecer la diferencia. De ahí la importancia de contar con una cláusula adecuada para los contratos de gestión delegada que se suscriban, por lo que nos atrevemos a proponer para discusión del foro, cláusulas modelo para los contratos de gestión delegada, la misma que planteamos como punto de partida para la discusión del asunto.

\section{INTRODUCCIÓN DE UN NOVEDOSO MÉTODO ALTERNO DE SOLUCIÓN DE CONFLICTOS:}

\section{La Junta de Resolución de Disputas}

El artículo 20 de la Ley en discusión, en su último inciso, establece lo siguiente:

Las partes podrán pactar arbitraje o dictámenes técnicos de conformidad con términos y estipulaciones previstos en el contrato de gestión delegada para resolver controversias puramente fácticas surgidas durante la ejecución o liquidación del respectivo contrato. 
A simple vista no es fácil comprender el artículo, pues creemos que comete un error al incluir la palabra "arbitraje". La legislación ecuatoriana prevé dos tipos de arbitrajes: en derecho y en equidad. Cuando sea en derecho, sólo los abogados podrán actuar en calidad de árbitros, mientras que si es en equidad, cualquier persona puede ser designada árbitro. En nuestra Constitución solo se prevé que el Estado solo podrá someterse a arbitrajes en equidad, cuando se trate de contratos relacionados con la deuda externa que contrate el Estado ecuatoriano ${ }^{21}$.

No obstante, en este inciso en particular, se hace referencia a un "arbitraje técnico", en el que se resolverá sobre cuestiones "puramente fácticas", surgidas durante la ejecución. También, el artículo lo llama "dictamen técnico". Un dictamen técnico es un documento final emitido por un perito -experto en la materia objeto de la controversia- que resuelve respecto a un punto controvertido en alguna ciencia o arte. Entendiéndolo así, evidentemente, el experto que la ley busca para resolver cuestiones puramente técnicas en materia de obras públicas e inversión extranjera, no es un abogado, sino un experto en estas materias (por ejemplo, ingeniero o economista). Pero si un grupo de ingenieros o economistas tomaran una decisión en un arbitraje, en calidad de árbitros, legalmente la institución sería entendida como un arbitraje en equidad.

Analizando el fondo de la disposición y el contexto en el que se expide, se evidencia claramente que la intención de los creadores de esta norma fue instituir un mecanismo que se llama en la práctica y legislaciones extranjeras como Junta de Resolución de Disputas. Este mecanismo se encuentra en auge en la región, siendo adoptado por nuestros países vecinos, siendo uno de los casos más recientes en el Perú22.

Definitivamente, esta herramienta es la más eficiente para resolver disputas en el ámbito del derecho de construcción, debido a que muchos de los conflictos que surgen durante la ejecución

21. CRE, N. 1, Artículo. 422.

22. Ley de Contrataciones del Estado, (Ley No. 30225), DO, 11/07/2014. 
contractual dificultan o paralizan el avance de las obras, necesitando una solución rápida, con el fin de evitar desajustes en los cronogramas establecidos o la terminación del contrato por un mero desacuerdo en ciertos aspectos del contrato. El arbitraje es en sí un proceso, que involucra una serie de etapas y formalidades que debe cumplir obligatoriamente, lo que lo convierte en un mecanismo más lento para solucionar una disputa. En cambio la Junta de la Resolución de Disputas es un método hecho a la medida para estos tipos de contratos ${ }^{23}$.

La Junta de Resolución de Disputas (Dispute Resolution Boards), es un mecanismo alternativo de solución de disputas por el que las partes escogen a uno o varios expertos (independientes e imparciales) en la materia del contrato para que se familiaricen con el proyecto y, surgida una controversia en su ejecución, la resuelvan, de manera que las partes puedan retomar rápidamente el cumplimiento de las obligaciones contractuales.

En principio, la Junta de Resolución de Disputas debe tomar decisiones vinculantes y de inmediato cumplimiento para las partes, siendo impugnables sólo en vía arbitral o judicial y debiendo cumplirse esta decisión hasta el momento en que el fallo o laudo dicte lo contrario. También, existe la posibilidad de que la decisión que tome la Junta sea no vinculante, en tal caso se expedirá una recomendación. Esto dependerá del tipo de Junta que se pacte: Junta de adjudicación (Dispute Adjudication Board), que es obligatoria, o Junta de revisión (Dispute Review Board), mera recomendación..$^{24}$ Recordemos que la naturaleza de este mecanismo es contractual.

Es de vital importancia aclarar un punto: las Juntas de Resolución de Disputas no son enemigas del arbitraje. De hecho, podríamos incluso decir que estos mecanismos se complementan,

23. M. Castillo Freyre, "Un nuevo amigo del arbitraje: los dispute boards", Revista Arbitraje PUCP, Centro de Análisis y resolución de conflictos, Año IV(4), 2014, pp. 45-53.

24. C. Bernavente Leigh, y E. Sotelo Gamarra, "Novedades en los Mecanismos de Resolución de controversias en etapa de ejecución contractual de la nueva ley de contrataciones del Estado", Revista Arbitraje PUCP, Centro de Análisis y resolución de conflictos, Año IV(4), 2014, pp. 21-27. 
debido a que la Junta es un mecanismo más eficiente para resolver las disputas que necesitan una solución urgente para continuar con la ejecución del contrato, y las decisiones que tome este organismo colegiado pueden ser cuestionadas en arbitraje, en donde deberá considerarse si, de acuerdo a Derecho, la decisión fue correcta ${ }^{25}$.

Consideramos que cuando la ley utiliza el término "dictámenes técnicos" no solo entra en esta expresión las Juntas de Resolución de Disputas, pues también creemos que permite la posibilidad de pactar otras figuras, tales como el expert determination, o someter los conflictos a la decisión de los colegios especializados, como los colegios de ingenieros, arquitectos, etc.

\section{Propuesta de cláusulas modelos para los CONTRATOS DE GESTIÓN DELEGADA}

\subsection{Primer párrafo: mediación o diálogos directos}

\section{Mediación}

Las partes manifiestan su acuerdo de someter a mediación cualquier controversia o reclamación que surja de o se relacione con este contrato. La mediación será administrada por el (nombre del centro), conforme a su (reglamento de mediación). Cualquier controversia o reclamación que no hubiere sido resuelta, dentro de los 45 días siguientes a la notificación de la solicitud de mediación por escrito, deberá ser planteada en la vía administrativa.

\section{Diálogos directos}

Las partes manifiestan su acuerdo de someter cualquier controversia o reclamación que surja de o se relacione con este contrato a diálogos directos entre las partes. Los diálogos directos se 25. M. Castillo Freyre, N. 23. 
entenderán iniciados al momento de la notificación de la controversia o reclamación surgida, que hace la parte que se siente perjudicada a la otra parte. Cualquier controversia o reclamación, que no hubiera sido resuelta mediante acuerdo final y definitivo dentro de los 45 días siguientes a la notificación de inicio de los diálogos directos, deberá ser planteada en la vía administrativa.

\subsection{Segundo párrafo: Regulación de la vía administrativa}

\section{Remitirse a una ley}

(En caso de mediación previa)

Suscrita el acta de mediación parcial, de imposibilidad de acuerdo, o constancia de imposibilidad de mediación, el gestor privado deberá agotar la vía administrativa conforme a lo dispuesto en el (COOTAD/ERJAFE), en cuyo caso los plazos correspondientes empezarán a decurrir al día siguiente de suscrita el acta o constancia correspondiente, o en su defecto, al día siguiente de vencidos los 45 días antes mencionados.

(En caso de diálogos directos previos)

Transcurridos 45 días sin que las partes lograren un acuerdo mediante diálogos directos, las partes podrán interponer los reclamos o recursos administrativos que fueren del caso para agotar la vía administrativa, conforme a lo dispuesto en el (COOTAD/ ERJAFE), en cuyo caso los plazos correspondientes empezarán a decurrir al día siguiente de vencidos los 45 días antes mencionados.

\section{Regularlo las partes}

Suscrita el acta de mediación parcial, de imposibilidad de acuerdo, o constancia de imposibilidad de mediación, el gestor privado deberá plantear su reclamo administrativo dentro de los 
30 días siguientes de suscrita el acta o constancia correspondiente, o en su defecto, dentro de los 30 días siguientes de vencidos los 45 días antes mencionados para agotar la mediación o los diálogos directos. La entidad delegante deberá contestar el reclamo dentro de los 30 días siguientes de presentado el reclamo administrativo.

Se entenderá agotada la vía administrativa si la entidad delegante niega, total o parcialmente, el reclamo administrativo, o contesta sin un pronunciamiento expreso sobre las pretensiones del gestor privado. También se entenderá agotada la vía administrativa si trascurridos 30 días desde la presentación del reclamo administrativo, la entidad delegante no notificare una respuesta al reclamo administrativo planteado.

\subsection{Tercer párrafo: arbitraje administrado o independiente}

\section{Arbitraje administrado}

Agotada la vía administrativa, las partes dispondrán de 30 días para presentar su petición de arbitraje. Este plazo empezará a decurrir al día siguiente de notificada la resolución adoptada por la entidad delegante, o al día siguiente de vencido el plazo para contestar el reclamo administrativo, si la entidad delegante no contesta el reclamo administrativo dentro del plazo previsto en esta cláusula.

Las partes declaran su voluntad de someter a arbitraje (nacional/internacional) toda controversia o reclamación que no haya sido resuelta entre las partes en las fases anteriormente estipuladas. El arbitraje será en Derecho y administrado por (nombre del centro), de conformidad con su (reglamento de arbitraje), cuyas normas las partes declaran conocer y aceptar.

El tribunal arbitral estará compuesto por (uno/tres) árbitro(s), y serán designados uno por cada parte, y el tercero por 
acuerdo de las partes, y a falta de este acuerdo, mediante sorteo conforme al (reglamento de arbitraje). La sede del arbitraje será (ciudad - país) y el idioma será el español.

Las partes acuerdan facultar al tribunal arbitral para dictar medidas cautelares y solicitar, para la ejecución de dichas medidas, el auxilio de los funcionarios públicos, judiciales, policiales y administrativos, sin necesidad de recurrir a juez ordinario alguno.

No serán materia de arbitraje las acciones que por su naturaleza sean de competencia del Tribunal de lo Fiscal, ni la expedición de leyes o regulaciones sectoriales que afecten el servicio materia de este Contrato.

\section{Arbitraje independiente}

Las partes declaran su voluntad de someter a arbitraje (nacional/internacional) toda controversia o reclamación que no haya sido resuelta entre las partes en las fases anteriormente estipuladas. El arbitraje será en Derecho e independiente. El arbitraje se llevará a cabo bajo la (escoger Ley) y el (escoger reglamento).

El tribunal arbitral estará compuesto por (uno/tres) árbitro(s), los cuales serán designados (elegir forma de designación). La sede del arbitraje será (ciudad - país) y el idioma será el (español/inglés/portugués).

Las partes acuerdan facultar al tribunal arbitral para dictar medidas cautelares y solicitar, para la ejecución de dichas medidas, el auxilio de los funcionarios públicos, judiciales, policiales y administrativos, sin necesidad de recurrir a juez ordinario alguno.

No serán materia de arbitraje las acciones que por su naturaleza sean de competencia del Tribunal de lo Fiscal, ni la expedi- 
ción de leyes o regulaciones sectoriales que afecten el servicio materia de este Contrato.

\section{Conclusiones}

Sobre la base de lo expuesto, nos permitimos formular las siguientes conclusiones:

a) La Ley APP constituye una iniciativa positiva para la recepción del arbitraje como mecanismo de solución de conflictos con el Estado ecuatoriano, aun cuando establece restricciones y limitaciones en su aplicación.

b) Los artículos 19 y 20 de la Ley APP consagran la posibilidad de pactar cláusulas arbitrales en los contratos que se suscriban al amparo de dicha Ley, sin modificar el esquema general de requisitos y autorizaciones previas previstas en el artículo 190 de la Constitución, artículos 4 y 42 de la LAM y en el artículo 11 de la LOPGE; es decir, que para pactar la cláusula arbitral solo se requiere autorización del Procurador General del Estado cuando se trate de arbitraje internacional.

c) La Ley APP solo permite pactar arbitrajes internacionales sometidos a organismos regionales latinoamericanos, por lo que se excluye la posibilidad de pactar arbitrajes sometidos a los principales centros de solución de controversias mundiales (American Arbitration Association, Comisión Interamericana de Arbitraje Comercial, International Chamber of Commerce, etc.), por lo que las posibilidades de pactar arbitraje internacional se limitan a centros de arbitraje con sede en países latinoamericanos (Centro de Arbitraje y Conciliación de la Cámara de Comercio de Bogotá, Centro de Arbitraje y Mediación de la Cámara de Comercio de Lima, Centro de Arbitraje y Mediación de la Cámara de Comercio de Santiago), o centros regionales de arbitraje, que de acuerdo a nuestra investigación, hasta la fecha no existen. 
d) La Ley APP establece un escalonamiento de la cláusula arbitral, exigiendo previamente la celebración de una mediación o de diálogos directos, y en ambos casos, el agotamiento de la vía administrativa. Este tipo de cláusulas dificulta el inicio del arbitraje, pudiendo incluso impedir el acceso al mismo para el gestor privado, por lo que se vuelve necesario regular adecuadamente dicho escalonamiento en la cláusula arbitral.

e) El artículo 20 de la Ley APP exige el agotamiento de la vía administrativa previo al inicio de un arbitraje, y como se trata de un procedimiento reglado que tiene algunas complejidades, es recomendable regular el fin de la vía administrativa en la cláusula arbitral, sea remitiendo a un ordenamiento jurídico que lo regule (ERJAFE, COOTAD), o estableciendo reglas de procedimiento en la propia cláusula arbitral.

f) La Ley APP contempla la posibilidad de pactar dictámenes técnicos, lo cual resulta novedoso en nuestro ordenamiento jurídico, pero no es extraño para la práctica arbitral internacional, pues a nivel de doctrina y derecho comparado encontramos que la figura prevista en la Ley APP no es otra que las juntas de resolución de disputas (dispute resolution board), que son mecanismos empleados para la resolución de determinadas diferencias en contratos de construcción o de obra pública. Concluimos que las resoluciones o dictámenes técnicos que a futuro se dicten en los conflictos que surjan de los contratos de gestión delegada amparados en la Ley APP, bien pueden ser discutidas en arbitraje.

g) El artículo 15 de la Ley APP contempla la posibilidad de otorgar estabilidad tributaria y regulatoria sectorial en los contratos de gestión delegada, pero los asuntos tributarios y otros relacionados con la potestad legislativa o regulatoria del Estado, son materias excluidas del arbitraje. Concluimos que los asuntos tributarios y regulatorios sectoriales no son materia arbitrable, siempre y cuando la aplicación de la ley o normativa sectorial no entrañe una violación de la estabilidad tributaria otorgada al gestor privado en el contrato de gestión delegada, en conformidad con el referido artículo 15 de la Ley APP. 